\section{THE COMMON INSECTS OF JORTH AMERICA}

By Lester A. Swan and Charles Papp.

Harper and Row Publishers, Inc., 10 East 3rd Street, New York, N.Y. 750 pp., 1972. 15.00 (U.S.)

This book is meant to provide any nterested person with a much needed, asy way to identify the common inects of North America north of Mexico. Text and description are ninimized and emphasis is placed on lack and white pictures and sketches or identification of the orders and pecies. The book is intended for the ayman without formal courses in enomology as well as for the general iologist and specialist. To ensure that he readers may better understand the ook's context brief general disfussions of biology and classification supplemented with drawings) preface he main part of the text.

Some 1,400 major species of insects n 23 main orders are illustrated and liscussed. Discussions include infornation on distribution, food plants and types of injury, animal hosts, inect growth and size, time of occurrence, etc.

A bibliography of some 370 titles is ncluded of which about 30 are Canadian. To evaluate in part the legree to which Canadian species of nsects may have been overlooked, the ist of species occurring in the 1971 Annual Report for the Forest Insect and Disease Survey, Canadian Forestry Service, was checked against he index of species included in this ook. Of approximately 115 recorded $n$ the Survey report, only some 50 pecies are included in this book.

Despite its shortcomings, this publication is a real contribution to entomology by bringing together a great deal of information on insects, pitherto found largely in separate eaflets, journals, etc., and available mainly to specialists. It will not provide answers to all questions and oroblems of insect identification enountered by laymen, general piologists or specialists but it will go ar towards meeting many of their needs both in the U.S.A. and Canada. The fact that identification is brought to the species level makes this publication better than other publications which fail to do so. It should prove practical and valuable as a reference source on insects for the high school library. - Lloyd O. T. Peterson, Indian Head, Sask.

\section{THE SNIPES: A STUDY OF THE GENUS CAPELLA}

By Leslie M. Tuck.

Canadian Wildlife Service Monograph Series, No. 5. 429 p. Information Canada, Ottawa. 1972. $\$ 7.50$.

I heard that sound again this morning - a sure sign that it is May. A sound that is felt as much as heard; a sound that shares spirit-like origins with the call of the Loon; a sound whose production puzzled scientists for over 100 years; the sound of "winnowing" or "bleating" of the Wilson's Snipe.

The production of this sound and all aspects of behaviour, systematics, mor phology, ecology and management of this genus are methodically covered in this book. The text is well documented and illustrated. Dr. Tuck writes in a style that is most readable and which is equally appealing to the amateur and professional ornithologist. It is this ability to combine original, significant information with a very readable style that has won him the Wildlife Society's Terrestrial Publications Award in 1962 for his book The Murres, and again in 1973 for The Snipes. One can not find fault with content or format.

It is worthwhile to consider that both of Tuck's monographs and Erskine's Buffleheads are the products of long-term field investigations. Such long-term research is the only way in which such an accumulation of knowledge can be obtained. One wonders if the recent trend in government policy towards short-term research will bring an end to the Monograph Series. As a reader, a biologist and a concerned citizen I sincerely hope not. - Glen A. Fox, Edmonton, Alberta. 
ALBERTA VIREOS AND

\section{WOOD WARBLERS}

Families Vireonidae and Parulidae. Distribution and Breeding.

By W. R. Salt.

Provincial Museum and Archives of Alberta, 12845 - 102nd Ave., Edmonton, Alberta. 141 p. $\$ 4.50$.

This is the third book in the Alberta Provincial Museum and Archives' publication series. The author is an Honourary Member of the Federation of Alberta Naturalists and is best known as the co-author of Birds of Alberta.

Using a vast amount of data too detailed for inclusion in Birds of Alberta, Dr. Salt provides a thorough description of the distribution, migration and nesting of the 4 vireos and 30 wood warblers occurring in Alberta.

Under "Distribution" and "Subspecies" there is a general description of the range and abundance of each species, and a brief description of the range of each subspecies. This is followed by a long list of localities giving local abundance in certain localities throughout the province and a full page map of the breeding range of each subspecies in the province.

Under the heading of "Nesting", there is a well-written description of the nest itself, its site, the general habitat preferred for nesting as well as a discussion of the habits of the bird near the nest. There follows a documented list of locations and dates for nests in Alberta.

In the section on migration early dates of arrival and late dates of fall departure are given for several localities throughout Alberta. Information on hybridization and parisitism is included for a few species. There is also a list of 120 references.

Unfortunately, for a book on warblers and vireos, no attention is paid in the text to their identification. The book does include a series of paintings of fall plumages but these are, in the opinion of the reviewer, too pale. This may be due to faded museum specimens used, to poor reproductio or to the original paintings. Also th fact that only one individual of each the 34 species is shown makes it little help in identification since the is such a wide variation in colour fall warblers of a particular species.

For Alberta birdwatchers, th volume will be useful as a guide when and where they may find eac species. For all birdwatchers, th section on nesting should be of valt in helping them find nests of the wa blers and vireos covered. - Str. Shadick,. Saskatoon, Sask.

\section{A SIMULATION MODEL FOR TH MANAGEMENT OF SANDHILL CRANES}

By Richard S. Miller, George S. Hoc baum and Daniel B. Botkin.

Bull. No. 80 School of Forestry and E vironmental Studies, Yale University. $\mathrm{Ne}$ Haven, Connecticut. 49 p. 1972. \$2.50.

Miller et al. combine a critic review of Sandhill Crane manageme with their presentation of a simulatic model designed to demonstrate the $c$ fects that change in demographic fa tors can have upon the populatic dynamics of cranes. The stated pu pose of their study was "to suggest th kinds of data required for prop management of the species ..." and "help focus our thinking and point o the crucial gaps in our knowled about the population dynamics Sandhill Cranes ..." In reality t authors have interwoven theoretic considerations with practic criticisms of current crat management to such an extent that must conclude that criticism management appears to have been primary objective.

Their main concern hinges up their apparent belief that in the face recreational hunting pressure, Sandh Cranes "could enter into a long-ter decline in population size before $t$ evidence of such a decline was dete ted, and that the species might becor endangered before it was returned protected status." They have evident 


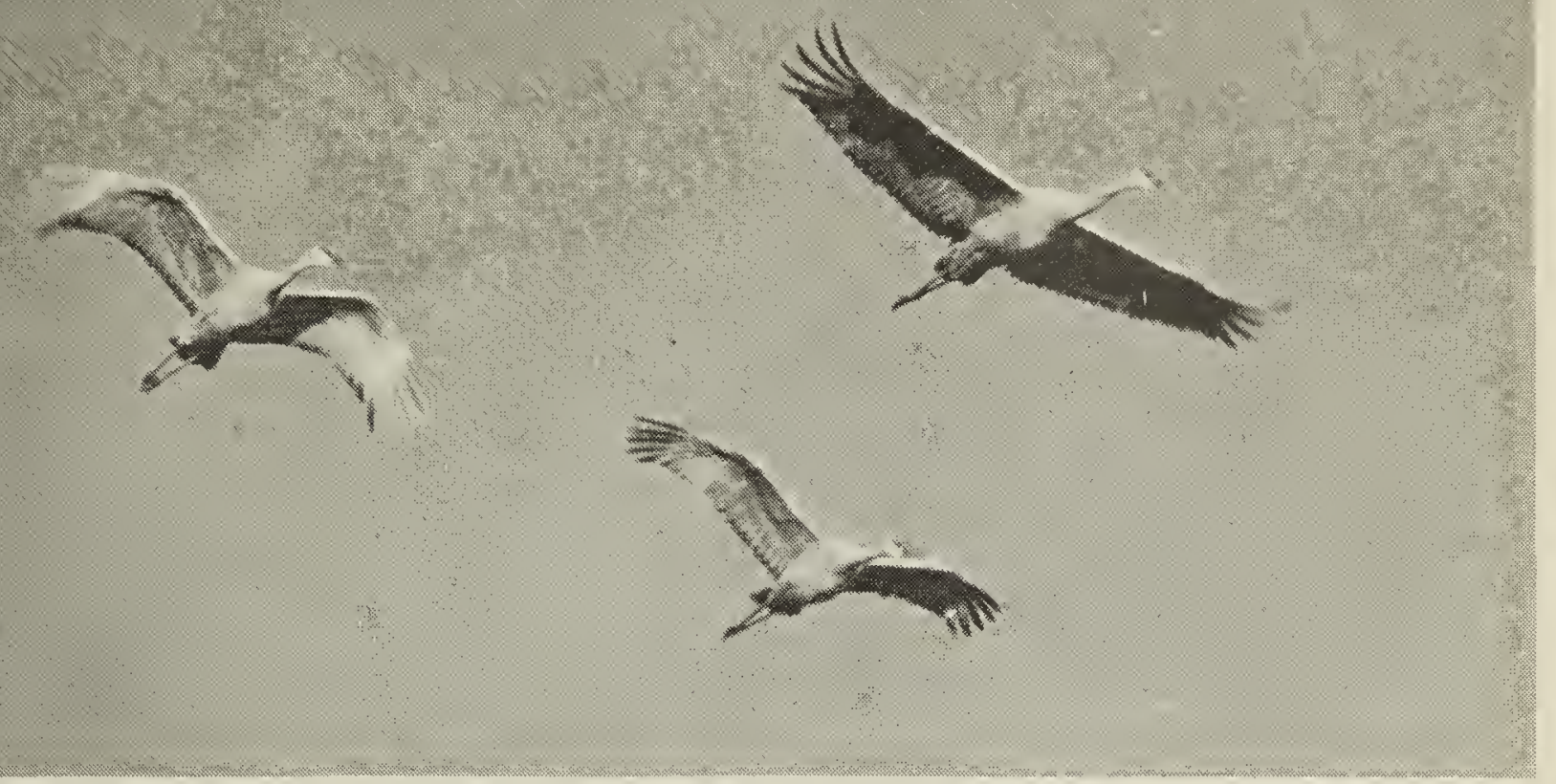

fandhill Cranes in flight.

Fred Lahrman

Irrived at this conclusion through a ubjective evaluation of current crane urveys and highly theoretical projecions of the dynamics of a crane opulation exposed to different levels of simulated hunting. The conclusion $s$ drawn despite their own qualifying tatement that "These projections are made merely to illustrate a variety of ossible hunting situations and to show imitations of the existing data; it hould be clear that the projections hould not be taken literally."

The average number of cranes couned during preseason surveys in New Mexico and Texas over an 11 -year period is about 195,000 cranes with he lowest being 135,000 in the first ear of the survey. The total number of ranes is estimated at 300,000 on the pasis of these and other surveys. Miller $t$ al. interpret the variable nature of he survey to mean that a decline in rane numbers would not be detected intil the population fell below 35,000 and that, by the time it was letected, the population could already e in serious trouble. This seems to me 0 be a misinterpretation of the fapabilities of the annual survey. The urvey has so far dealt with an apparently stable crane population and las yielded average counts of about 65 percent of the estimated population. It is illogical to assume that if the population declined the accuracy of the survey would increase concurrently to produce results similar to previous years and that managers would therefore not suspect a decline until the population actually fell below 135,000 or about 45 percent of its currently estimated level.

Miller et al. have succeeded in pointing out the need for accurate measurements of demographic parameters of Sandhill Cranes but in my opinion their criticisms of current management are too easily discredited.

For a scholarly publication, this one has an incredible number of editorial shortcomings such as no pagination in the Table of Contents; all figures without numbers or legends in the text; no references cited for important population data and at least three references cited in the text but omitted from the Literature Cited. - A. Brian Ransom, Boissevain, Manitoba.

Editor's Note: Life history dat.. as given in this bulletin is as follows: Sandhill Cranes probably begin to breed in their 4th year and live 20 to 25 years. Two eggs is the most frequent number in a nest but usually only one young survives to migrate south. On the average, about 30 young are produced per 100 adults. There are apparently no data on mortality rates for this species in the wild. 